УДК 929(470.23-25)

\title{
С.А. Пономарёва
}

\section{ФИНАНСОВО-ХОЗЯЙСТВЕННАЯ ДЕЯТЕЛЬНОСТЬ Г.И. СПАССКОГО ДЛЯ ОБЕСПЕЧЕНИЯ ИЗДАНИЯ «СИБИРСКОГО (АЗИЯТСКОГО) ВЕСТНИКА» В 1817-1827 гг.}

\begin{abstract}
Рассматривается финансово-хозяйственная сторона издательской деятельности Г.И. Спасского в $1818-1827$ гг. Исследование имеет целью выяснение вопроса, были ли финансовые затруднения издателя причиной прекращения издания. Также рассматривается сотрудничество Г.И. Спасского с В.В. Дмитриевым, который считается его соиздателем (по крайней мере, при издании первой части «Сибирского Вестника»).

Ключевые слова: Г.И. Спасский; В.В. Дмитриев; «Сибирский Вестник»; «Азиятский Вестник»; издательское дело.
\end{abstract}

С января 1818 по июнь 1827 г. в СанктПетербурге выходило первое в России периодическое издание, посвященное исследованию Сибири и «прилежащих к ней стран», - «Сибирский Вестник», переименованное в 1825 г. в «Азиятский Вестник». Его издатель Г.И. Спасский посвятил 14-летнее свое пребывание на сибирской службе собиранию материалов о древнем и современном состоянии Сибири, проводя археологические, этнографические и лингвистические исследования, сделав десятки географических, статистических и исторических описаний различных уездов Томской губернии и Алтая. Материалы для публикации в «Сибирском Вестнике» доставляли также томские губернаторы В.С. Хвостов и П.К. Фролов, государственный деятель и реформатор М.М. Сперанский, сообщавший чрез своего секретаря К.Г. Репинскаго документы из архива Сибирского комитета и своего личного архива, члены Русской духовной миссии в Пекине Е.Ф. Тимковский, С.В. Липовцов и М.Д. Сипаков, историк В.Н. Берх и многие другие. Общий объем номеров журнала, изданных за неполные 10 лет, превысил 440 печатных листов ${ }^{1}$. Но издание было внезапно прервано в середине 1827 г., а о причинах прекращения не известно ничего. Однако известно, что после прекращения издания «Сибирского (Азиятского) Вестника» Г.И. Спасский продолжал публикацию статей «сибирской» тематики в сторонних журналах. В Государственном архиве Красноярского края, в фонде № 805 [1], содержится большое количество документов, которые также подтверждают, что «коллекция» собранных сибирских материалов не была исчерпана Спасским, а прекращение издания было вызвано внешними причинами. Существует мнение, что одной из этих причин были финансовые затруднения, испытываемые издателем журнала. «Больше всего затруднений представлял... денежный вопрос»: такая точка зрения была высказана первым биографом Г.И. Спасского - Б. Смирновым [2. С. 114]. Данное исследование имеет целью выяснить вопрос, были ли финансовые затруднения издателя причиной прекращения издания.

Тираж и расход «Северного (Азиятского) Вестника». В сентябре-ноябре 1817 г. В.В. Дмитриев и Г.И. Спасский, сочлены по Вольному обществу любителей словесности, наук и художеств, задумали и осуществили подготовку издания периодического издания, посвященного исследованиям Сибири.

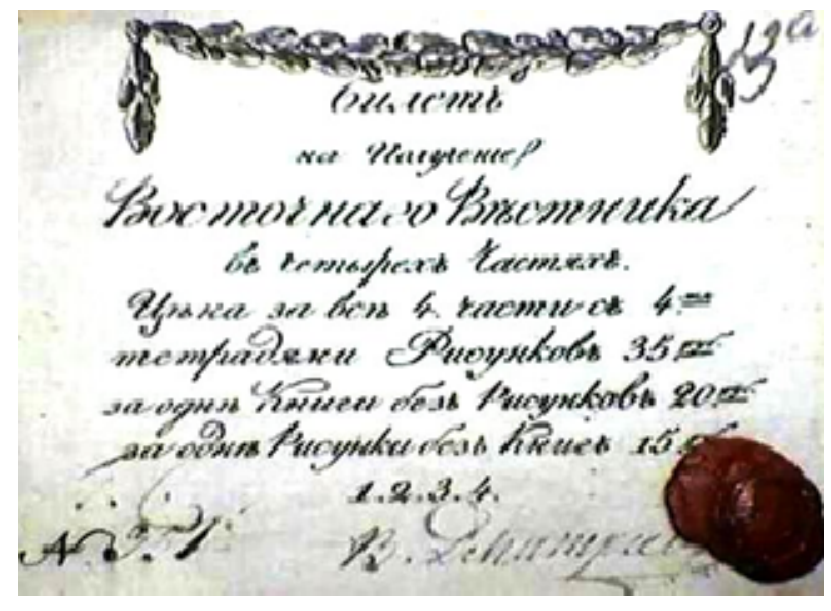

Рис. 1. Билет на получение «Восточного Вестника» № 357 за подписью В.В. Дмитриева

Изначально предполагалось дать журналу название «Восточного Вестника». Г.И. Спасский занимался более литературными трудами, а организационными вопросами - преимущественно В.В. Дмитриев, имевший уже опыт издательской деятельности². Дмитриевым был составлен план издания ${ }^{3}$, предполагавший:

1) величину тиража в 1200 экземпляров (обычный размер тиража - так называемый завод);

2) объем 1-й книги в 15 печатных листов, т.е. примерно в 240 страниц формата «в осьмую долю» 4

3) отдельное издание тетради из 12 гравированных рисунков: «как у Лаперуза, Шатобриана, Кука и других путешественников, для того что тетрадь рисунков сама по себе составит уже редкость» [1. Д. 293. Л. 29], в количестве, равном основному тиражу;

4) печатать «Восточный Вестник» в 3 частях, «из коих первая выдет в генваре, вторая в мае, а третья в сентябре будущзаго 1818 года» [Там же. Л. 30];

5) «...для того, чтобы не понести убытка от переплета», журнал выходил в так называемой печатной обложке. Переплетались особо только подарочные экземпляры и те, которые следовало представить в казенные учреждения.

Затем в план были внесены коррективы: тираж совместным решением уменьшили до 600 экземпляров (сохранились расчеты В.В. Дмитриева по затратам на издание именно 600 экз.), причем эта величина тиража оставалась неизменной во все время издания; по крайней мере в апреле 1824 г., после шести лет из- 
дания, Г.И. Спасский сообщал М.М. Сперанскому именно о таком количестве печатаемых экземпляров. Прочие изменения были внесены решением одного только Г.И. Спасского: изменено название журнала на «Сибирский Вестник», объем номера уменьшен (1-я книга была печатана в 9 листов, а полный объем издания за 1818 г. составил 35 листов); в год стало выходить не три, а четыре части.

Изначальная договоренность соиздателей заключалась в равном несении расходов, оттого и предполагаемую от реализации первого номера журнала прибыль в 30-48 тыс. руб. планировали делить «средним числом», из которого надлежало «иметь ввиду на печатание» дальнейших частей. Однако «расход» (т.е. peaлизация) тиража был невелик и не достигал половины напечатанного. В конце 1821 г. Г.И. Спасский сообщал, что расход этого издания простирался «...кругльмм числом в течении четырех лет немного более 200 екземпл. на каждый год...» [1. Д. 214. Л. 2 об.-3], а в 1824 г. Спасский пишет, что у него остаются «...екземпляры книг (числом до 400)» [Там же. Л. 10]. Не все «разошедшиеся» экземпляры были проданы. Из числа изданного должны были предоставляться в Цензурный комитет 6 экз., в Императорскую публичную библиотеку -2 , в Особенную канцелярию - 1 экз. [Там же. Д. 293. Л. 33], кроме того, около дюжины или немногим более экземпляров Г.И. Спасский дарил приятелям и научным обществам.

В первый год выхода журнала Г.И. Спасский столкнулся с непорядочностью соиздателя: В.В. Дмитриев в начале 1818 г. без предупреждения покинул Санкт-Петербург и не вернул компаньону уговоренной половины денег за 69 розданных им подписных билетов (см. рис. 1), а еще в 18 билетах и вовсе не дал никакого отчета [Там же. Д. 9. Л. 3-3 об.]. Поэтому при подсчете прибыли, полученной Г.И. Спасским, будет разумно принять за величину реализации в первый год числа в 120 экз., в последующие - не более 200 экз., а 1827 г. из-за прервавшегося издания - вполовину меньшее количество.

Стоимость подписки. Согласно первоначальному плану стоимость подписки на «Восточный Вестник» должна была составить «без фигур и рисунков 25 руб., с фигурами и рисунками 40 руб., тетрадь фигур и рисунков особенно 15 руб. Каждый в особенности Сибирский вид или костюм из тетради сей по ${ }^{1} / 2$ руб. серебром ${ }^{5} »[$ Там же. Д. 293. Л. 30]. Открывалась годовая и полугодовая подписка. Впоследствии было решено сократить стоимость годовой подписки до 20 35 руб. в зависимости от комплектации номера тетрадкой рисунков. В дальнейшем цена подписки менялась следующим образом: в 1819 г. - от 22,5 до 30 руб. для жителей столицы и от 25 до 35 - для иногородних [5. 1818. Ч. III]; в 1820 г. издание стало ежемесячным, годовая подписка составила сумму в 25 руб. для Санкт-Петербурга и 30 для иногородних, полугодовая - вполовину меньше [Там же. 1819. Ч. VIII]; с 1822 г. при сохранении стоимости годовой подписки увеличилась стоимость полугодовой до 15 и 18 руб. - для петербуржцев и иногородних соответственно. В этом же году было объявлено, что желаю- щие могут приобрести «Сибирский Вестник» за 18181821 гг.,: все четыре выпуска за 80 руб., а порознь за 25 руб. В 1823 г. были внесены изменения в план журнала, он стал выходить 2 раза в месяц - объем издания увеличился более, чем вдвое по сравнению с первым годом. Увеличилась и стоимость годовой подписки: для петербуржцев она составила 30 руб., а для иногородних - 37 руб. ассигнациями. Читатели также уведомлялись, что выход в свет «Сибирского вестника» в 1823 г. будет зависеть от числа подписавшихся на журнал: если количество таковых будет невелико, то выпуск журнала стал бы невозможен, и Спасский обязывался вернуть уплаченные деньги.

Летом 1824 г. Спасский объявил о начале продажи «Географического и Статистического описания Сибири и ея островов», печатаемого помимо журнала «Сибирский Вестник». Цена его в двух частях объявлялась в 15 руб. для жителей столицы и в 20 руб. с пересылкою в прочие города. Ранее напечатанные при номерах «Сибирского Вестника» части «Описания Сибири» продавались по 5 и 7 руб. соответственно. Переименовав в 1825 г. «Сибирский Вестник» в «Азиятский», Г.И. Спасский вернулся к ежемесячным выпускам, сохранив стоимость 1824 г. - 30 руб. для жителей столицы, а с пересылкой - 35 руб. Всем полным подписчикам «Азиятского Вестника» издатель обещал с каждым номером доставить 1-2 листа продолжения «Географического и Статистического описания Сибири» бесплатно, приложением в виде «особливых листов» [5. 1824. Ч. III. Кн. 13-14]. Эти же условия подписки сохранились и в 1826 г. [6. 1825. Кн. 7]; необходимо заметить, что последние 6 номеров «Азиятского Вестника» за этот год допечатывались в следующем 1827 г.; эта задержка последовала, по-видимому, от введения в действие в июне 1826 г. нового Цензурного устава («Чугунного устава»). Г.И. Спасский, уведомив своих читателей в июньской книжке «Азиятского Вестника» об этой задержке, сообщил и цену подписке на 1827 г.: она оставалась неизменной, равно как и план самого издания. Единственным изменением было прекращение печатания «Описания Сибири» [Там же. 1826. Кн. 6]. Однако в 1827 г. после выхода первых шести книг издание вообще было остановлено и более не возобновлялось.

Расходы на издание 6 . О них известно из упомянутого выше «плана» В.В. Дмитриева, который писал в октябре 1817 г. Спасскому: «Вы желаете знать, чего будет стоить печатание 1-й части в 600 екземпляров, вот оно: за набор каждого листа в 8-ю долю 6 р. 50 к., печатание 600 лист. 9 р. 38 к., каждый лист без бумаги 15 p. 88 к., на каждый лист бумаги 1 стопа 6 дестей и и листов - 15 руб. 9 коп. Итого лист в 600 екземпляров будет стоить 30 р. 97 коп. Билеть 600 стоят за доску 10 рублей за напечатание и бумагу по 2 коп. 12 руб., [итого] 22 руб. Публикация... будет стоить 36 руб. 3 коп.» [1. Д. 293. Л. 35 об. -36].

Отдельный расчет должно осуществлять для гравированных изображений. До появления литографического способа, значительной удешевившего печатание рисунков, иллюстрации создавались граверами и их услуги стоили недешево и скорость работ была 
невысока. Рисунки для первого номера (12 видов) выполнял сам В.В. Дмитриев, придававший иллюстрациям особенное значение: «Хотя глаза мои чуть смотрят, но к завтрашнему и тетрадь рисунков готова будет...», «...рисунки более всего меня заботят, а там за настоящее дело - ибо книги зависят от нашего ума, а механизм от ума других. Однако же механизм сей весьма значителен, а более с франиузским языком ${ }^{8}$, и чуть ли мы не прославим себя, а особливо перед дамскою публикою, да и вообще перед народом непрестанно лепечущим соблазнительным языком сим здесь и в Москве» [Там же. Л. 32, 48 об.]; поэтому стоимость изготовления 12 гравюр была относительно невелика - 1000 руб. (по расчетам В.В. Дмитриева). Полная цена выполнения гравированного рисунка, без «скидок» также известна: она составляла в зависимости от сложности и размера от 100 до 250 руб. [1. Д. 257. Л. 3; 9. С. 414].

Стоимость переплета книг достигала 1 руб. за один экземпляр [9. С. 414], но издателю приходилось переплетать за свой счет лишь одну-две дюжины подарочных и казенных экземпляров. В число прочих мелких расходов следует отнести также траты на чистовую переписку рукописей для типографии, гужевой транспорт, рассылку номеров журнала подписчикам. Общий расход компаньонов на печатанье тиража первой части должен был составить не менее 1380 руб., но надо полагать, что со всеми неучтенными расходами мог достигать 1500 руб. ассигнациями. Последующие журнальные выпуски 1818 г. были существенно дешевле, так как не приходилось нести затраты на печатание рисунков и билетов; оставшиеся три книги этого года содержали 26 листов, а себестоимость их печатания достигала круглым числом 850 руб. В последующий год Г.И. Спасский продолжил печатание отдельных тетрадок с «видами и фигурами», а начиная с 1820 г. начал комплектовать рисунками книжки журналов. Всего было напечатано около 40 иллюстраций: две тетрадки с 23 гравюрами с «сибирскими видами» и «древностями Сибири», 4 вида Алтайских «местоположений», 5 гравюр - с изображением киргизской юрты и национальных костюмов, 2 вида монгольских «ламайских капищ», 2 портрета завоевателя Сибири - Ермака, а также прочие рисунки, карты и схемы [1. Д. 1. Л. 5-6]. Обилие рисунков на начальном этапе привело предприятие Г.И. Спасского на грань финансового краха; издатель вошел «...особливо по причине помещченных в первые два года гравированных изображений, в необходимылй долг, составляющиий до 3 m.[вссяч] рублей, который крайне затрудняет продолжение дальнейтего его издания〉 [1. Д. 214. Л. 2 об. - 3].

Немалый убыток Г.И. Спасский понес от действий своего компаньона. В.В. Дмитриев из-за ведения какой-то посторонней тяжбы испытывал постоянную нужду в деньгах и, вместо внесения своего пая, то и дело «по дружески» одалживал мелкие суммы у Спасского: 17 октября 1817 - «все посланное от вас... исправно получил - денег 15 руб. и прочее»; 9 ноября «...объявление естли не вылио сегодня, то во вторник выдет непременно. Причиною тому единственно то, что не могу достать необходимо нужных для того денег... Естли у вас есть сколько-нибудь, пришлите завтра часу около 2-го. Я, получа по обещзанному, возвраму, а не получа, употреблю в пользу»; 3 января 1818 - «Прикажите заплатить за извозчика, да ежели есть что нибудь за лишком, то пришлите мне, хотя безделииу и 10 руб. много значут. Завтра пошлю и получа возврашу - пожалуйте, действуйте по дружески, и ради Бога с человеком что-нибудь пришлите, ибо завтра еду я к граверу - и он будет у меня просить»; 4 января - «пришлите сколько-нибудь мне денег. У меня право до случая нет ничего. Поделитесь хоть малостью сегодня, а завтра увидимся» [1. Д. 293. Л. 21, 41-41 об.; 28; 38]. Из-за денежных затруднений соиздателя на Спасского легла вся тяжесть финансирования предприятия. После побега В.В. Дмитриева из столицы (в конце января 1818 г.), Г.И. Спасский с укоризной писал ему в село Петрищево: «Отьезд ваш отсюда не видевшись и не простясь со мною довольно странный, удивил меня, особенно судя по той приязни вашей ко мне, в которой никогда не преставали меня уверять. Скоро появится в свет и Сибирский Вестник. Чтобы выполнить данные обещчания и сохранить доверенность к себе публики, сколько надобно было мне преодолеть затруднений и сделать сколько пожертвований для сего издания; а за всем тем, сколько еще впереди подлежит мне оных... По выходе первой части снабжу оною и взнесших вам подписныя деньги, хотя нисколько из сих денег ${ }^{9}$ и ваших собственных не поступало ко мне на сие издание» [Там же. Д. 293. Л. 39, 40 об.]. Дмитриев обещал Спасскому найти «потерянные» билеты, а долг выплатить, но тяжелая болезнь и смерть, настигшая его в январе 1820 г., помешали ему выполнить финансовые обязательства.

Случались убытки и по непредвиденным обстоятельствам. Так, в ноябре 1824 г. в Санкт-Петербурге случилось крупнейшее наводнение, погубившее большое количество людей и животных, разрушившее здания. Погиб очередной тираж «Сибирского Вестника», а работа в типографиях была приостановлена; издатель был вынужден в экстренном порядке заново печатать сдвоенные номера, переместив выпуск последней 4-й части на начало 1825 г.

Общая сумма, потраченная Спасским на 10-летнее издание, поддается лишь приблизительной калькуляции: исходя из того что общий объем издания превысил четыре сотни листов ${ }^{10}$; с учетом изготовления гравюр, погубленного полугодового тиража в 1824 г. и неполного тиража 1827 г. себестоимость отпечатанного приближалась к 20 тысячам рублей, возможно, была несколько большей. Г.И. Спасский неоднократно обращался к правительству с просьбой о воспомоществовании - в 1821 г. он просил «пособия как на выплату... долга, так и для дальнейшего продолжения Сибирского Вестника» [1. Д. 214. Л. 3], а в апреле 1824 г. ходатайствовал о следующем: «...из числа печатаемых мною 600 екземпляров Сибирского Вестника более половины остается на моих руках... Чтобы сии екземпляры не лежали без всякого употребления $и$ вместе не делали мне весьма чувствительного убыт-

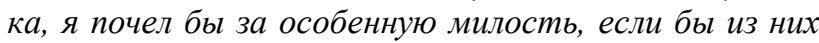


до 225 приняты были в казну для учебных заведений с выдачею мне по 16 рублей за екземпляр, то есть почти по половинной цуене против объявленной для вольных покупателей; что составит за пять лет сего издания, а именно с 1818 по 1823 год 18 m[висяч] рублей» [Там же. Д. 382. Л. 7 об. - 8]. Эти просьбы, по всей видимости, не были удовлетворены. Нельзя, однако, сказать, что труды Г.И. Спасского «для пользы соотечественников» остались незамеченными. Они были вознаграждены дважды: в 1824 г. - пожалованием бриллиантового перстня ${ }^{11}$ (обычная стоимость награды от 200 до 400 руб.), а также пожалованием Спасского «...nо всеподданнейшему докладу Министра Народнаго Просвещения в награду ученьх трудов, на пользу общую окружающих орденом Святого равноапостольного князя Владимира 4 степени 1825 марта 29-го» [1. Д. 2. Л. 4 об. - 5]. Эти скромные в финансовом смысле поощрения, разумеется, не могли компенсировать всех затрат, но к чести Г.И. Спасского надо заметить, что он был готов к материальным пожертвованиям: «Движимылй ... стара- нием к пользе общей, которая не может быть никогда ни излишнею, ни предосудительною, я решился бороться со всеми препятствиями, и в течении сряду шести лет неутомимо продолжал Сибирский Вестник...» [1. Д. 375. Л. 3 об.]

Общая прибыль от издания, так же как и затраты, может быть рассчитана только приблизительно; в первые годы издание было убыточным, но думается, что начиная с 1822 г. положение выправилось и издание начало приносить небольшой доход. Принимая величину реализации номеров журнала за 1820 1826 гг. по 200 экземпляров в год, можно вычислить минимальную сумму доходов от реализации журнала в 35-40 тыс. руб. Не ручаясь за точность абсолютных цифр, можно все же с достаточной степенью уверенности предположить, что мнение о денежных затруднениях Г.И. Спасского, связанных с издательской деятельностью, не является верным, и, во всяком случае, отнюдь не финансовые потери издателя стали причиной прекращения «Сибирского (Азиятского) Вестника».

\section{ПРИМЕЧАНИЯ}

\footnotetext{
${ }^{1}$ Без учета объема «Географического и Статистического описания Сибири и ея островов».

${ }^{2}$ В 1809 г. вышел первый и единственный номер журнала «Ореады», издателем которого был В.В. Дмитриев.

3 Этот «бизнес-план» частично опубликован, без его финансового отделения, К.В. Анисимовым [3. С. 131-132].

${ }^{4}$ Размеры «физического» бумажного листа составляли около $50 \times 70$ см, но никогда не соблюдались точно: например, использовалась бумага $42 \times 68,44 \times 71,46 \times 72$ см и т.п. с соотношением сторон, приближенным к так называемому золотому сечению; «Сибирский Вестник» и «Азиятский Вестник» печатался «ин октаво» или в $8^{\circ}$ - это формат, получаемый фальцовкой листа в три сгиба, говоря проще, из одного «листа» получалась тетрадка в 16 страниц. Высота книжного блока составляла 21-22 см, ширина 14-15 см.

5 рубля ассигнациями (по курсу 1817 г.) [4. С. 29].

${ }^{6}$ Суммы указаны в ассигнациях, иное оговаривается отдельно; курс серебряного рубля в $1817-1827$ гг. изменялся от 4 до 3,58 руб. ассигнациями [4. С. 27-29].

В 1 стопе, как и в 1 дести, количество листов не было точно определено, считалось, что в 1 стопе бумаги столько же, сколько в 20 дестях; в начале XX в. Брокгауз и Ефрон определяют величину «стопы» в 480 листов [7. С. 708], хотя в конце XIX в. в этой же энциклопедии «десть» определяется в 24 листа, а «стопа» - в 24 дести [8. С. 488]; очевидно, что В.В. Дмитриев считал стопу бумаги в 450 листов, а десть в 24 листа, цену же бумаге определял в 2,5 коп. за лист.

${ }^{8}$ Подписи к рисункам на французском языке делал Г.И. Спасский.

${ }^{9}$ Речь может идти о довольно крупной сумме денег; учитывая не внесенный пай за издание и утаенные от компаньона деньги за 87 билетов - от 2500 до 3800 руб.; однако в записках В.В. Дмитриева значилось поступление к нему от реализации билетов только 175 руб., а остальные были розданы в долг.

${ }^{10}$ В 1818 г. объем «Сибирского Вестника» составил 35 листов, в 1819 г. - 25, в 1820 г. -41 , в 1821 г. - 41 , в 1822 г. - 56, в 1823 г. - 72 (!), в 1824 г. - 59 листов; объем «Азиятского Вестника» в 1825 г. - 57 листов, в 1826 г. - 43; за 6 месяцев 1827 г. - 20 листов.

${ }^{11}$ Об этом пожаловании Г.И. Спасский упоминает в 1825 г. в письме к Н.А. Полевому, издателю «Московского телеграфа» : «Августейшая покровительница полезных трудов, Им. Ек. Ал. удостоила своим благоволением, пожсаловав мне богатый бриллиантовый перстень» [1.
} Д. 255. Л. 2 об.].

\section{ЛИТЕРАТУРА}

1. Государственный архив Красноярского края. Ф. 805 (Г.И. Спасского).

2. Смирнов Б. «Григорий Иванович Спасский: Материалы к биографии» // Сибирские огни. 1927. № 1. С. 110-122.

3. Анисимов К.В. «Поэтика литературы Сибири 10-30 годов ХІХ столетия». Томск : Изд-во Том. ун-та, 2004. С. 100.

4. Малышев А.И., Таранков В.И., Смиренный И.Н. Бумажные денежные знаки России и СССР. М., 1991. С. 496.

5. Сибирский Вестник, издаваемый Григорием Спасским. СПб. : Тип. Иоаннесова, 1818-1824.

6. Азиятский Вестник, содержащий в себе избранныя сочинения и переводы по части наук, искусств и словесности стран восточных, равно путешествия по сим странам и разные новейшия сведения / Издаваемый Григорием Спасским. СПб. : Тип. Мед. Департ. м-ва внут. дел, $1825-1827$.

7. Брокгауз Ф.А., Ефрон И.А. Энциклопедический словарь. Т. ХХХІ-а : Статика - Судоустройство. СПб., 1901.

8. Брокгауз Ф.А., Ефрон И.А. Энциклопедический словарь. Т. Х-а : Десмургия - Домициан. СПб., 1893.

9. Смирнов-Сокольский Н. Рассказы о прижизненных изданиях Пушкина. М., 1962. С. 632.

Статья представлена научной редакцией «История»1 марта 2016 г.

\section{FINANCIAL AND ECONOMIC ACTIVITY OF GRIGORY I. SPASSKY IN ORDER TO SUPPORT THE PUBLICATION OF SIBIRSKIY VESTNIK AND AZIATSKIY VESTNIK}

Vestnik Tomskogo gosudarstvennogo universiteta - Tomsk State University Journal, 2016, 406, 131-135. DOI: $10.17223 / 15617793 / 406 / 21$

Ponomareva Svetlana A. Siberian Federal University (Krasnoyarsk, Russian Federation). E-mail: vadjima72@gmail.com Keywords: Grigory I. Spassky; Vasily V. Dmitriev; Sibirskiy vestnik; Aziatskiy vestnik; publishing business. 
In the period from January, 1818 to June, 1827, there was the first periodical in Russia published in Saint Petersburg, which was dedicated to the investigation of Siberia and "some countries adjacent to it" - Sibirskiy Vestnik [Siberian Herald], which was renamed into Aziatskiy vestnik [Asian Herald] in 1825. Its publisher Grigory I. Spassky devoted his 14 years of being on Siberian service to the collection of materials on the ancient and modern state of Siberia, conducting archaeological, ethnographic and linguistic studies, having made dozens of geographical, statistical and historical descriptions of different counties of Tomsk Province and the Altai and the peoples inhabiting them. The total number of publications for 10 years was more than 440 printed pages. But the publication was suddenly interrupted in the middle of 1827, and the reasons of the cease of this publication remain unknown. However, it is known that after the cease of Sibirsky (Aziatskiy) vestnik publication, Grigory I. Spassky continued the publication of the articles on the "Siberian" topic in external magazines. There are a large number of documents in the State archive of Krasnoyarsk Krai, fund 805 , which also confirm that Spassky did not exhaust the "collection" of gathered Siberian materials, and the cease of the publication was caused by external reasons. The subject of the article is the financial and economic side of the publishing activity of Grigory I. Spassky in 1818-1827. The aim of the investigation is to clear up the question as to whether financial difficulties were the reason for the cease of the publication. A rough calculation of expenses on the publication, made by Grigory I. Spassky, and the amount of profits he earned on the realization of Sibirsky (Aziatskiy) vestnik ("Siberian (Asian) Herald") became possible in the result of the analysis of correspondence between Grigory I. Spassky and Vasily V. Dmitriev, who is considered to be his co-publisher (at least of the first part). The correspondence came around in the period from October, 1817 to March, 1818, at the opening stage of the magazine publication organization, and contains unique details of relationships between the co-publishers; particularly, it imparts the understanding of the reasons of the break between the partners. Generally, the investigation disproves the popular opinion that the publication of Sibirsky (Aziatskiy) vestnik was attended with a financial loss for Grigory I. Spassky, and suggests that this business was at least run without a loss.

\section{REFERENCES}

1. State Archive of Krasnoyarsk Krai (GAKK). Fund 805 (G.I. Spassky). (In Russian).

2. Smirnov, B. (1927) Grigoriy Ivanovich Spasskiy: Materialy k biografii [Grigory Spassky: Materials for the biography]. Sibirskie ogni. 1. pp. 110122.

3. Anisimov, K.V. (2004) Poetika literatury Sibiri 10-30 godov XIX stoletiya [Poetics of Siberian Literature in the 1810s-1830s]. Tomsk: Tomsk State University.

4. Malyshev, A.I., Tarankov, V.I. \& Smirennyy, I.N. (1991) Bumazhnye denezhnye znaki Rossii i SSSR [Paper banknotes of Russia and the USSR]. Moscow: Finansy i statistika.

5. Sibirskiy Vestnik. (1818-1824). Published by Grigory Spassky. St. Petersburg: Tipografiya Ioannesova.

6. Aziyatskiy Vestnik. (1825-1827). Published by Grigory Spassky. St. Petersburg: Tipografiya Med. Depart. ministerstva vnutrennikh del.

7. Brockhaus, F.A. \& Efron, I.A. (1901) Entsiklopedicheskiy slovar' [Encyclopedic Dictionary]. Vol. XXXI-a. St. Petersburg: F.A. Brockhaus, I.A. Efron.

8. Brockhaus, F.A. \& Efron, I.A. (1893) Entsiklopedicheskiy slovar' [Encyclopedic Dictionary]. Vol. X-a. St. Petersburg: Tipo-Litografiya I.A. Efrona.

9. Smirnov-Sokol'skiy, N. (1962) Rasskazy o prizhiznennykh izdaniyakh Pushkina [Stories of the lifetime editions of Pushkin]. Moscow: Izdatel'stvo Vsesoyuznoy knizhnoy palaty. 